\title{
Detection of specific antibodies in cows after injection of PPD ${ }^{1}$
}

\author{
Carla D. Marassi ${ }^{2 *}$, Carlos Zarden ${ }^{2,3}$, Walter Oelemann ${ }^{4}$ and Walter Lilenbaum ${ }^{2}$ \\ ABSTRACT.- Marassi C.D, Zarden C., Oelemann W. \& Lilenbaum W. 2014. Detection of spe- \\ cific antibodies in cows after injection of PPD. Pesquisa Veterinária Brasileira 34(3):241- \\ 243. Laboratório de Bacteriologia Veterinária, Departamento de Bacteriologia e Parasitoló- \\ gica, Universidade Federal Fluminense, Rua Professor Hernani Mello 101, Lab. 309, Niterói, \\ RJ 24210-130, Brazil. E-mail: carladray@yahoo.com.br \\ The diagnosis of bovine tuberculosis aims to identify the immune response against \\ mycobacterial antigens. Although Single Intradermal Comparative Cervical Tuberculin test \\ (SICCT) is broadly used for first identification of the disease, the performance of ELISAs \\ has been investigated for diagnosis improvement. The present study expected to find out \\ the influence of intradermal skin tests on the results of ELISAs using the recombinant pro- \\ teins MPB70 and MPB83 as antigens on cows from a naturally infected herd. Results were \\ analyzed by the F-test, Mann-Whitney and Friedman tests Although comparable to both \\ proteins, results showed that positive animals presented a tendency of augment reactivity \\ to MPB70, representing a tendency for a booster effect, but not to MPB83.
}

INDEX TERMS: ELISA, tuberculosis, cattle, MPB70, MPB83, interference.

\begin{abstract}
RESUMO.- [Detecção de anticorpos específicos em vacas após a injeção de PPD.] 0 diagnóstico da tuberculose bovina baseia-se na identificação da resposta imune do animal frente aos antígenos de Mycobacterium bovis. Embora o teste intradérmico comparativo cervical seja o mais empregado como primeiro teste diagnóstico, outras técnicas, como ELISA, tem sido investigadas para aumentar a detecção de animais infectados. 0 presente estudo analisou se os testes intradérmicos influenciariam os resultados de ELISAs que utilizaram as proteínas MPB70 e MPB83 como antígenos de captura em um rebanho naturalmente infectado. Os resultados foram analisados por meio de testes estatísticos de comparação e correlação de resultados: teste-F, Mann-Whitney e Friedman. O desempenho de ambos os ELISAs foi comparável; no entanto, os resultados demonstraram que entre os animais positivos, houve um aumento de reatividade ao MPB70, dado este que não foi observado junto ao ELISA-MPB83.
\end{abstract}

\footnotetext{
${ }^{1}$ Received on October 15, 2013.

Accepted for publication on March 17, 2014.

${ }^{2}$ Laboratório de Bacteriologia Veterinária, Departamento de Bacteriologia e Parasitologia, Universidade Federal Fluminense (UFF), Rua Professor Hernani Mello 101, Lab. 309, Niterói, RJ 24210-130, Brazil. *Corresponding author: carladray@yahoo.com.br

${ }^{3}$ Departamento de Morfofisiologia Veterinária, Centro de Ciências Agrárias, Universidade Federal do Piauí, Campus Socopo, PI 64049-550, Brazil.

${ }^{4}$ Departamento de Imunologia, Instituto de Microbiologia, Universidade Federal do Rio de Janeiro (UFRJ), Cidade Universitária, Rio de Janeiro, RJ 21941-902, Brazil.
}

TERMOS DE INDEXAÇÃO: ELISA, tuberculose, bovinmos, MPB70, MPB83, Interferência.

\section{INTRODUCTION}

Single Intradermal Comparative Cervical Tuberculin test (SICCT), using purified protein derivative (PPD), is the most common current method for the diagnosis of bovine tuberculosis (bTB) (Schiller et al. 2010). The test measures cell-mediated immune response (CMI). Additionally, as serological tests could detect anergic animal, they can be employed as complementary tools (Waters et al. 2011, Marassi et al. 2013). Many proteins have been suggested as capture antigens for specific immunoglobulins, and MPB70 and MPB83 showed encouraging results, achieving 63\% of sensitivity and $98 \%$ of specificity (Lyashschenko et al. 2001, Waters et al. 2011).

In addition, the time schedule and frequency of PPD inoculation interferes with the cellular immune response, and 60 to 90 days are normally required before another skin test can be performed, due to the desensitization of the animal (Thom et al. 2004, Palmer et al. 2006). In an outbreak situation, cattle must be monitored most often and periodical skin testing is compulsory. In those conditions, the impact of PPD inoculation on humoral response, detected by ELISA, remains unclear. Furthermore, animals can be in different stages of the infection, which could interfere on the efficacy of SICCT (Alvarez et al. 2012, Marassi et al. 2013). In that way, the purpose of this study was to detect 
specific antibodies at MPB70/83 ELISAs in cows after injection of PPD.

\section{MATERIALS AND METHODS}

This study was approved by the Ethics Committee of Universidade Federal Fluminense (CEPA-UFF), protocol 0234/12. A dairy herd located in Rio de Janeiro, Brazil, presented an outbreak of bTB indicated by a routine SICCT, after newly acquired cows were introduced. After 90 days, a confirmatory skin testing was performed in all 68 adult ( $>6$ months) cows of the herd. In parallel to that confirmatory SICCT, blood samples were collected at the same day of the injection of PPD (day 0) and on days 3, 7, 21 and 35 days post injection (p.i.). Serum samples were used in the MPB70 and MPB83-ELISAs, performed according to Marassi et al. (2011).

Intradermal tests. They were performed in accordance with the regulations of the Brazilian Department of Agriculture. After $72 \mathrm{~h}$, the injection site was measured with calipers; a cow was considered reactive if a swelling $>4.0 \mathrm{~mm}$ was detected. For SICCT, $0.1 \mathrm{~mL}$ of bovine PPD (bovPPD-M. bovis strain AN5, 1mg protein/ $\mathrm{mL}$; Instituto Biológico, São Paulo, SP, Brazil) was injected in the cervical area. Also in the cervical area, animals received a shot of $0.1 \mathrm{~mL}$ avian PPD (Mycobacterium avium strain D4, 0.5mg protein/mL; Instituto Biológico) about $20 \mathrm{~cm}$ away from the bovPPD inoculation. Cattle were considered reactive if the difference between the thicknesses of the two injection sites exceeded $4.0 \mathrm{~mm}$.

ELISAS MPB70/MPB83. The recombinant proteins MPB70 and MPB83 were prepared and purified as described by Alito et al. (2003). Each antigen was used separately as a capture antigen in an IgG-ELISA; it was diluted $(1 \mathrm{mg} / \mathrm{mL})$ in a $0.05 \mathrm{M}$ carbonate buffer ( $\mathrm{pH}$ 9.8) and used to coat a 96-well plate (Nunc maxisorb1-USA) overnight at $8 \circ \mathrm{C}$. After six washes, the plate was blocked with $2 \%$ casein (Sigma, USA) in TBST (10mM Tris; 0.9\% NaCl; 0.1\% Tween20, pH 7.5; all components were purchased from Sigma, USA) solution for $60 \mathrm{~min}$ at room temperature with constant agitation. The plate was washed again and bovine sera, diluted to 1 in 100 in TBST buffer containing 1\% casein, were added to the wells. The incubation was performed at $37{ }^{\circ} \mathrm{C}$ under continuous agitation for $60 \mathrm{~min}$. As a secondary antibody, an alkaline-phosphatase conjugated anti-bovine IgG was used (1/5000), and the reaction was revealed with $1 \mathrm{mg} / \mathrm{mL}$ p-NPP (para-nitrophenyl phosphate), then stopped with $2 \mathrm{~N} \mathrm{NaOH}$ (Merck, USA) after 30min in the dark. Optical density (OD) readings were measured using a spectrophotometer (model 680 BioRad, USA) at a wavelength of $405 \mathrm{~nm}$.

Statistics. The performance of the tests was analyzed separately. A correlation and comparison of both ELISAs were also analysed. F-test, Mann-Whitney and also Friedman test were used for analysis.

\section{RESULTS}

From the 68 animals tested, nine were reactive in SICCT $(13.2 \%)$. Noteworthy that according to Brazilian and international recommendations (OIE 2009), all the nine cows were infected, regardless the direct confirmation. All the nine SICCT-reactive cows were kept apart from the rest of the herd during the study and were slaughtered in the farm after the last blood collection (day 35 p.i.). At necropsy, although only two of them presented characteristic gross lesions at necropsy, such as tubercles with central caseation and calcification, or circumscribed yellowish white lesions in lungs or lymph nodes. From the nine cows mediastinal, bronchial lymph nodes, and lung samples were collected and processed for culture and PCR (Figueiredo et al. 2009).
At MPB70-ELISA, considering the 59 negative cows (SICCTneg), none of the samples were reactive on days 0 or 3p.i.. However, reactivity was observed for one serum taken at day 7p.i., five taken at day 21p.i., and 16 taken at day 35p.i. Considering the nine positive cows (SICCTpos), one was reactive on day 0 and day 3 and two on days 21 and 35 p.i.. None of the cows was reactive on day 7p.i. Conversely, considering MPB83-ELISA results, from the 59 negative cows, eighteen were reactive on day 0 ; eight on day 3 p.i., two on day 7 p.i., five on day 21 p.i. and only one on day 35 p.i. These results are depicted in table 1 . From both tested proteins, a significant difference between SICCTneg and SICCTpos was observed, with average OD values of SICCTpos animals greater than the average of negative animals (MPB70: $\mathrm{P}<0.0001$; MPB83: $\mathrm{P}=0.010$ ).

Analyzing the MPB70-ELISA results for the two groups (SICCTpos and SICCTneg animals), an increase of OD average values occurred in all animals, with a significant difference from day 35 p.i to day $0(\mathrm{P}=0.007)$, representing a tendency for a booster effect. Nevertheless, although MPB83-ELISA showed a slight overall decrease of average OD values from day 0 to day 35 p.i. $(P=0.09)$; the differen-

Table 1. Number of serum samples (one for each animal) reactive to MPB70/MPB83-ELISAs and single intradermal comparative cervical tuberculin test (SICCT) results

\begin{tabular}{ccr}
\hline & SICCT $(-)$ & SICCT $(+)$ \\
\cline { 2 - 3 } & $\mathrm{N}=59$ & $\mathrm{~N}=9$ \\
MPB70 & & 1 \\
Day 0 & 0 & 1 \\
Day 3 & 0 & 0 \\
Day 7 & 1 & 2 \\
Day 21 & 5 & 2 \\
Day 35 & 16 & \\
MPB83 & & 6 \\
Day 0 & 18 & 4 \\
Day 3 & 8 & 0 \\
Day 7 & 2 & 2 \\
Day 21 & 5 &
\end{tabular}

ces between SCITTpos and SCITTneg animals $(p=0.0001)$ could still be observed in several moments of the study, according to Fig.1.

\section{DISCUSSION}

In the present study, apart for sera from day 7p.i. when ODs were lower, ODs of animals tested by MPB70-ELISA presented a significant increase, regardless the infection status of the cows. Conversely, animals tested by MPB83-ELISA presented a decrease on OD values along the experiment. Unlike other authors that have identified a booster effect on MPB83-ELISA after intradermal skin tests (Lyaschenko et al., 2004), the slight decrease observed in our study could be credited to a mild desensitization effect. Noteworthy that this effect was not significantly different among the different times of the study ( $\mathrm{p}=0.09)$. MPB70 and MPB83 are both components of PPD (Borsuk et al. 2009) that could explain the booster effect observed for MPB70, but not the slight mild desensitization for MPB83. 


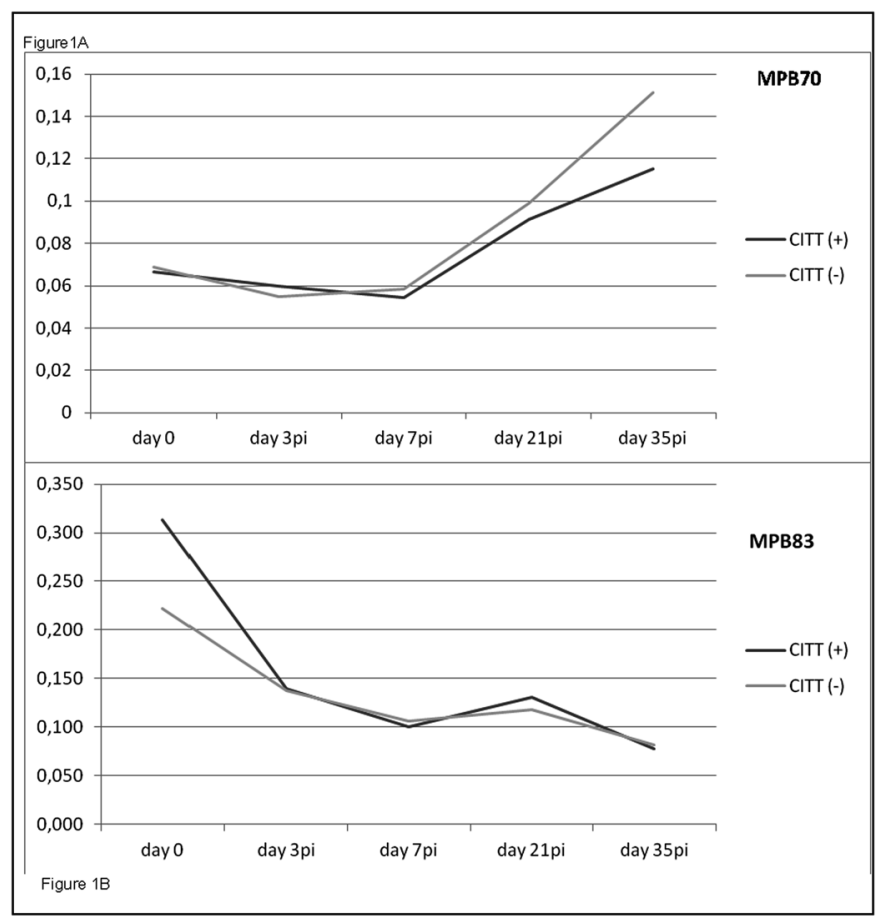

Fig.1. (A) MPB70-ELISA: mean OD values at each time of testing of SICCT (+) and SICCT (-) animals; cut off $=0.21$. (B) MPB83-ELISA: mean OD values at each time of testing of SICCT (+) and SICCT $(-)$ animals; cut off $=0.25$. SICCT $=$ Single Comparative cervical intradermal test.

More animals reacted against MPB83 than MPB70 at the day " 0 ", regardless of the status of the animal. Therefore, the reactivity observed on non-infected cows could be explained by a cross reactivity with some environmental mycobacteria, such as M. kansassi, what was referred to secret MPB83 in higher concentration than MPB70 (Waters et al. 2011). Furthermore, animals react in different moments against different antigens, and MPB83 is known to be detected earlier than MPB70 (Lysachenko et al. 2004). Thus, the possibility that some of the negative animals that reacted against MPB83 were in fact early infected cannot be excluded. In fact, four of them were reactive to SICCT five months after this first test (data not shown).

Since the experiment presents some limitations, as the small number of animals and the time that we could follow them, a booster or a desensitization effect could not be clearly demonstrated. Thom et al. (2004) reported that the anamnestic effect is more evident in infected animals that present characteristic histological lesions. In the studied herd, only two of the animals presented characteristic histopathological findings, suggesting a recent infection. Indeed, epidemiological investigation revealed that bTB appeared in this herd after the acquisition of a few cows four months before the onset of the study. This could mean that the majority of the studied animals had not yet developed a strong humoral response, which could substantially be detected by ELISA. Although MPB70 and MPB83 are major components of bovPPD, their exact concentration in bovPPD is unknown, presumably leading to different immune response intensities in different animal populations (Álvarez et al., 2012). Additionally, the potency and compo- sition of PPDs may vary among different countries and manufacturers, leading to variable interference on serological assays (Thom et al. 2004, Borsuk et al. 2009).

\section{CONCLUSION}

Although positive and negative animals presented a tendency of augment reactivity to MPB70 on a 7-day period after the SICCT, the real effect of tuberculin intradermal tests in the humoral detection is complex and remains to be investigated, varying not only with the employed antigen, but also with the stage of the infection and the studied population.

Acknowledgements.- Authors would like to thanks to financial support of FAPERJ, CAPES e CNPq; Professor Dr. Jim McNair for providing the antigens for this study and Denis Otaka, Gabriel Martins, Bruno Penna and Ana Paula Loureiro for helping with the collection of samples.

\section{REFERENCES}

Alvarez J., Perez A., Bezos J., Marqués S., Grau S., Saez J.L., Mínguez O., Juan L. \& Dominguez L. 2012. Evaluation of sensitivity and specificity of bovine tuberculous diagnostic tests in naturally infected cattle herds using a Bayesian approach. Vet. Microbiol. 155:38-43.

Borsuk S., Newcombe J., Mendum T.A., Dellagostin D.A. \& McFadden J. 2009. Identification of proteins by tuberculin purified protein derivative (PPD) by LC-MS/MS. Tuberculosis 89:423-430.

Figueiredo E.E.S., Galindo F.S., Campos W.N., Furlanetto L.V., Medeiros L., Lilenbaum W., Fonseca L.S., Silva J.T. \& Paschoalin V.M.F. 2009. Identification of Mycobacterium bovis isolates by a Multiplex PCR. Braz. J. Microbiol. 40:232-233.

Lyaschenko K.P., Wiker H.G., Harboe M., McNair J., Komissarenko S.V. \& Pollock J.M. 2001. Novel Monoclonal antibodies against major antigens of Mycobacterium bovis. Scand. J. Immunol. 53:498-502.

Lyashchenko K., Whelan A.O., Greenwald R., Pollock J.M., Andersen P., Hewinson G. \& Vordemeier H.M. 2004. Association of tuberculin-boosted antibody responses with pathology and cell-mediated immunity in cattle vaccinated with Mycobacterium bovis BCG and infected with M. bovis. Infect. Immun. 72:462-2467.

Marassi C.D., Medeiros L., McNair J. \& Lilenbaum W. 2011. Use of recombinant proteins MPB70 or MPB83 as capture antigens in ELISAs to confirm bovine tuberculosis infections in Brazil. Acta Tropica 118:101-104.

Marassi C.D., Medeiros L., Figueiredo E.E.S., Fonseca L.S., Duarte R., Paschoalin V., Oelemann W.M.R. \& Lilenbaum W. 2013. A multidisciplinary approach to diagnose naturally ocurring bovine tuberculosis in Brazil. Pesq. Vet. Bras. 33:15-20.

OIE 2009. Bovine tuberculosis, in Terrestrial Manual, chapter 2.4.7. <http://www.oie.int/fileadmin/Home/eng/Health_standards/ tahm/2.04.07_BOVINE_TB.pdf>

Palmer M.V., Waters W.R., Thacker T.C., Greenwald R., Esfandiari J. \& Lyaschenko K.P. 2006. Effects on different tuberculin skin-testing regimens on gamma interferon and antibody responses in cattle experimentally infected with Mycobacterium bovis. Clin. Vaccine Immunol. 13:387-394.

Schiller I., Vordemeier H.M., Waters W.R., Whelan A.O., Coad M., Gormley E., Buddle B.M., Palmer M., Thacker T., McNair J., Welsh M., Hewinson R.G. \& Oesch B. 2010. Bovine tuberculosis: Effect of the tuberculin skin test on in vitro Interferon gamma responses. Vet. Immun. Immunopathol. 136:1-11.

Thom M., Morgan J.H., Hope J.C., Villareal-Ramos B., Martin M. \& Howard C.J. 2004. The Effect of repeated tuberculin testing of cattle on immune response and disease following experimental infection with Mycobacterium bovis. Vet. Immunol. Immunopathol. 102:399-412.

Waters W.R., Buddle B.M., Vordemeier H.M., Gormley E., Palmer M.V., Thacker J.P., Bannantine J.P., Stabel J.R., Linscott R., Martel E., Milian F., Foshaug W. \& Lawrence J.C. 2011. Development and evaluation of an enzyme-linked immunosorbent assay for use in the detection of bovine tuberculosis in cattle. Clin.Vaccine Immunol. 11:1882-1888. 